\title{
CONSIDERACIONES FILOSÓFICO-TEOLÓGICAS Y EDUCACIONALES DE LA “IDEOLOGÍA DE GÉNERO”
}

\section{PHILOSOPHICAL-THEOLOGICAL AND EDUCATIONAL CONSIDERATIONS OF THE “GENDER IDEOLOGY”}

\author{
Flavio Gutiérrez Velasco* \\ Recepción: 04 de julio del 2017 \\ Aceptación: 20 de agosto del 2017
}

\begin{abstract}
RESUMEN
Ante la gran preocupación de una gran mayoría de padres de familia del Perú de incluir en el currículo educativo la denominada "Ideología de género", el autor analiza el tema desde diversas perspectivas: filosóficas, fundamentada básicamente en el existencialismo humanista ateo de Simone de Beauvoir y en la ideología marxista; teológicas, resaltando que ésta contradice la visión bíblica-teológica de que el hombre ha sido creado a imagen y semejanza de Dios y que esta ideología es deconstructura de la célula fundamental de la sociedad, la familia; y educacionales puesto que esta implicaría que el género es fruto exclusivamente de la cultura y no de la naturaleza humana. Ante esta ideología el autor resalta la visión cristiana-humanista del hombre, a quien lo concibe como una unidad biopsico-social, hablando de dimensiones del hombre.
\end{abstract}

\section{PALABRAS CLAVE}

Ideología de género, humanista, cultura, naturaleza humana, deconstructora, currículo nacional, feminismo, antropología cristiana.

\begin{abstract}
Given the alarm the presence in the educational curriculum of the so-called "Gender Ideology" has generated among of a large number of Peruvian parents, the author analyzes the subject from different perspectives. First, from a philosophical perspective, based on the humanistic existentialism of Simon de Beauvoir and in Marxist ideology. Second, from a theological perspective, emphasizing that this ideology contradicts the biblicaltheological view that man was created in the image and likeness of God and that it constitutes a deconstruction of the fundamental cell of society, i.e., the family. Last, from an educational perspective, as such ideology would imply that gender is the result of culture alone and not human nature. Against "Gender Ideology", the author highlights the Christian-humanist vision of man that conceives it as a bio-psycho-social unit, speaking of the dimensions of man.
\end{abstract}

\section{KEY WORDS}

Ideology of gender, humanist, culture, human nature, deconstructive, national curriculum, feminism, Christian anthropology.

\footnotetext{
*Docente Asociado de la Universidad Femenina Sagrado Corazón. flaviogutierrez@unife.pe
} 


\section{"La ideología de género es la última rebelión de la creatura contra su condición de creatura" (Cardenal Ratzinger)}

\section{INTRODUCCIÓN}

Lo que me motivó a realizar esta investigación fue la marcha "Con mis hijos no te metas”, realizada el sábado 4 de marzo del 2017 en Lima y en otras ciudades del Perú, por padres de familia, en contra del gobierno que habría incluido en el Currículo Nacional la "ideología de género". ¿Qué encierra esta frase?, ¿qué consecuencias traería para la educación de los niños y adolescentes?, ¿contribuye a la destrucción de un fundamento sólido de la sociedad como es la familia?

Primeramente, debemos tener claro lo que conocemos como "ideología de género" y los diversos conceptos correlacionados como "sexo", "sexualidad", "género", "roles", "identidad de género", "igualdad de género”. En segundo lugar, analizaremos las bases filosóficas de esta ideología, sus implicancias en la construcción de la persona y un enfoque cristiano-humanista del ser humano. En tercer lugar, expondremos la posición de la Iglesia frente a esta corriente de pensamiento, que es de evidente rechazo fundamentándose en reflexiones bíblico-teológicas. Finalmente haremos algunas disgregaciones de las implicancias que traería el incluir esta ideología en el currículo nacional, disfrazada con muchos términos falaces como el "orgullo gay", "los derechos de las minorías", "trato igualitario".

\section{Conceptos básicos}

"Ideología de género": es una corriente de pensamiento que sostiene que las diferencias entre lo masculino y lo femenino, a pesar de estar fundamentadas en las obvias diferencias anatómicas entre varón y mujer, no corresponden a una naturaleza fija, sino que son unas construcciones culturales y convencionales, fundamentadas en los roles y estereotipos que cada sociedad asigna a los sexos ${ }^{1}$

Sexo: "Es el conjunto de características físicas, biológicas, anatómicas y fisiológicas de los seres humanos que los definen como hombre o como mujer. El sexo viene determinado por la naturaleza, desde el nacimiento": por el último par de cromosomas: $\mathrm{xx}=$ mujer. $\mathrm{xy}=$ varón.

\footnotetext{
${ }^{1}$ Los feministas buscan la igualdad entre varón y mujer, mientras que los ideólogos de género buscan una de-construcción de la familia, de la distinción de sexos.
} 
Género: "roles y conductas atribuidas por las diferentes sociedades y culturas a hombres y mujeres, entendidos desde una dimensión socio-cultural, y no exclusivamente biológica. El concepto de género es un concepto clave para hacer posible las responsabilidades del individuo, la familia, la comunidad y el Estado en la construcción de relaciones basadas en la igualdad de oportunidades y respeto a las diferencias". Para los defensores de la "ideología de género" lo masculino y lo femenino son exclusivamente construcciones socio-culturales. Desde una perspectiva de la antropología humanista, éstos son un modo de ser del hombre y de la mujer y no meramente construcciones socio-culturales. La persona es una sola, pero que posee múltiples dimensiones.

Rol de género: "del inglés gender, role, alude al conjunto de normas sociales y comportamiento generalmente percibidas como apropiadas para los varones y las mujeres en un grupo o sistema social dado en función de la construcción social que se tiene de la masculinidad y la feminidad”. Estos pueden cambiar según las diversas culturas.

Equidad de género: significa que tanto los hombres como las mujeres tienen la misma posibilidad de goce del ejercicio pleno de sus derechos humanos, pudiendo contribuir con el desarrollo nacional, político, económico, social y cultural. En este sentido la equidad de género estará orientada básicamente a ofrecer oportunidades justas a mujeres y hombres" (Wikipedia, la Enciclopedia libre).

Identidad sexual: "Percepción que cada individuo tiene sobre sí mismo, sobre su cuerpo y los rasgos físicos que presente, sin embargo, esta percepción puede o no corresponder con el sexo determinado al nacer, generalmente si la persona nace con genitales femeninos se considera una hembra, si por el contrario nace con genitales masculinos se considera un varón (Wikipedia, la Enciclopedia Libre).

La identidad sexual abarca tres aspectos: a) el sexo biológico: es la corporeidad de una persona, determinado por los cromosomas xx en la mujer y xy en el varón; b) sexo psicológico: vivencias psíquicas como varón o mujer; c) sexo sociológico o civil: la percepción del sexo por el entorno. Esto es fruto de procesos históricos y culturales. Así antes no se concebía que una mujer pueda conducir un tráiler o ser mecánica, en cambio ahora sí.

\section{Raíces ideológicas de la "ideología de género"}




\section{Materialismo y existencialismo ateo de Simone de Beauvoir.}

Nicolás Márquez y Agustín Laje, en su reciente publicación "El libro negro de la nueva izquierda. Ideología de género o subversión cultural" consideran a Simone de Beauvoir, perteneciente a la tercera ola del feminismo ${ }^{2}$, como la gestora de la "ideología de género". Esta afirmación procede de la tesis central de de Beauvoir "no se nace mujer: llega una a serlo", de su libro "El segundo sexo", publicado en 1949; siendo esta la obra en la más importante del s. XX en esta materia (Laje, 2016).

De Beauvoir es una militante marxista de la ultraizquierda convencida de un cambio cultural de fondo: en las costumbres, en las creencias, en la moral. Su concepción se enraíza en las propuestas teóricas de la Escuela de Frankfurt, el "neomarxismo" o "marxismo cultural". La tesis central de De Beauvoir es que el concepto "mujer" es socialmente construido, carece de esencia, es artificial y es siempre definido por su opresor: el hombre. Lo que pretende es romper con ese concepto cultural de mujer y recuperar una presunta "identidad perdida".

De De Beauvoir se adhiere a la corriente filosófica del existencialismo, cuyo máximo representante fue su pareja Jean Paul Sartre. El principio fundamental de esta corriente es que el hombre no tiene una esencia acabada, la existencia precede a la esencia. Así la realidad de ser mujer no tendría una esencia, éste es el resultado de procesos históricoculturales. Las consecuencias que se derivan de esta concepción son que no hay naturaleza humana, el hombre es como una tabula rasa sobre la que la cultura hará de él. Por ello el ser hombre o ser mujer, no están determinados por naturaleza alguna, sino por lo que la cultura hace de ellos.

Consideramos que lo que el hombre es, es producto de dos componentes: la naturaleza y la cultura, nacemos como hombres o mujeres, en lo cual se enraíza la masculinidad o la feminidad, pero tampoco se puede negar el influjo que ejerce la historia y la cultura en moldear esa masculinidad o femineidad: "El hombre es naturaleza, pero también es cultura: en ese orden" (Laje, 2016, p.79). Una muestra es que cuando la cultura lo engrandece, también se engrandece su naturaleza. El hombre como persona tiene múltiples dimensiones: natural-biológica, psicológica, espiritual, social; es una unidad, no podemos disociarla. En esta ideología de género el hombre moderno pretende liberarse incluso de las

\footnotetext{
${ }^{2}$ En la primera ola se ubica el feminismo ilustrado, liberal y sufragista; el feminismo marxista como segunda ola; y el "feminismo culturalista radical" y /o "neomarxista" como tercera ola, responsable de la germinación de la llamada "ideología de género" (p.75)
} 
exigencias de su propio cuerpo: se considera como un ser autónomo que se construye a sí mismo; una pura voluntad que se autocrea y se convierte en un dios para sí mismo.

La distinción entre sexo y género aparece clara en de De Beauvoir: el sexo es el hecho natural y el género el cultural, pero que en sí mismos no guardan ninguna relación relevante. El sexo simplemente es el dato natural, el género lo es todo; no importa lo que el cuerpo trae naturalmente, sino cómo se socializa el individuo. De ello se puede deducir que la opresión de la que es víctima la mujer tiene un carácter cultural. Por ello es necesario destruir la superestructura vigente: moral, religiosa, ideológica, jurídica, familiar, por otra que lleve a construir una nueva mujer: "no hay que creer que basta con modificar su situación económica para que la mujer se transforme; este factor ha sido y sigue siendo el factor principal de su evolución, pero en tanto no comporte las consecuencias morales, sociales, culturales, etc. que anuncia y exige no podrá aparecer la mujer nueva” (Laje, 2016, p.82).

Benedicto XVI considera que la "ideología de género" es una "falacia profunda”, pues "está en juego la visión del ser mismo, de lo que significa realmente ser hombres". Aludiendo a la tesis de Simone de Beauvoir considera que según esta "el hombre niega tener una naturaleza preconstituida por su corporeidad, que caracteriza al ser humano, tal como Dios le ha dado como hecho preestablecido, sino que es él mismo quien se la debe crear". Considera Benedicto XVI que en esta ideología "el hombre niega su propia naturaleza", que "se niega a hombres y mujeres su exigencia creacional de ser forma de la persona humana que se integran mutuamente". Igualmente expresa que la libertad de hacer se convierte en libertad de hacerse uno mismo y con ello se niega al hombre ser creatura de Dios, imagen de Dios y que se queda finalmente degradado en la esencia de su ser. "En la lucha por la familia está en juego el hombre mismo y se hace evidente que cuando se niega a Dios, se disuelve también la dignidad del hombre. Quien defiende a Dios, defiende al hombre", en una clara contraposición a lo que dice de De Beauvoir. El ser humano tiene una naturaleza propia y no puede ser solo fruto de los condicionamientos socio-culturales. (Benedicto XVI, 2012).

\section{Shulamith Firestone: la deconstrucción de la cultura}

Feminista radical canadiense, promotora de la deconstrucción de la cultura: "Las feministas tienen que cuestionar, no sólo toda la cultura occidental, sino también la 
organización de la cultura en sí misma, e incluso la propia organización de la naturaleza" (Citada por Laje, 2016, p. 83)

Esta deconstrucción de la cultura comporta no solo la destrucción de clases, sino también la diferencia de sexos, como lo expresa en "The dialectic of sex" (1970):

Asegurar la eliminación de clases sexuales requiere que la clase subyugada (las mujeres) se alce en revolución y se apodere del control de la reproducción; se restaure a la mujer la propiedad sobre sus propios cuerpos, como también el control femenino de la fertilidad humana incluyendo tanto las nuevas tecnologías como todas las instituciones sociales de nacimiento y unidad de los niños” (...) Así la nota definitiva (...) debe ser igualmente - a diferencia del primer movimiento feminista- no simplemente acabar con el privilegio masculino, sino acabar con la distinción de sexos misma: las diferencias genitales entre los seres humanos ya no importan culturalmente" (Anónimo, 2017).

El programa de Firestone se puede resumir en cuatro puntos: 1) Abolir la función reproductiva de la mujer con arreglo a las tecnologías de la reproducción artificial y la legalización del aborto, b) Lograr la absoluta independencia económica de mujeres y niños, lo que supone abandonar la economía capitalista y adoptar un sistema socialista, 3) Incluir a las mujeres y a los niños en todos los aspectos de la sociedad, destruyendo todo aquello que resguarde la individualidad y destruyendo las distinciones culturales hombre/mujer, adulto/niño, 4) Lograr la libertad de todas las mujeres y niños para hacer lo que sea que deseen sexualmente" (citada por Laje 2017, p.84).

Lo que indudablemente busca Firestone es la deconstrucción de la familia, con lo cual se destruiría uno de los grandes pilares de la sociedad, la familia, con todas las consecuencias que ello traería.

En la misma línea, Eisentein concluirá que "la clase sexual no es oprimida biológicamente, es culturalmente oprimida (citada por Laje, 2016, p.89).

Esta ideología de género busca una "liberación total" del hombre en todos los órdenes, tras la deconstrucción del lenguaje, de las relaciones familiares, de la reproducción, de la sexualidad, de la educación, de la religión, de la cultura. Cuando el hombre se libere de todo esto será libre, afirman sus defensores. Indudablemente una ideología de este tipo 
conduciría a un libertinaje, una libertad desenfrenada, a un caos moral, a una pérdida de la identidad humana.

\section{Implicancias teológicas de la "ideología de género".}

Si el género es una construcción cultural, si lo que se pretende es eliminar las diferencias entre hombre y mujer, porque cada uno elegiría el género al que pertenecer, es obvio que el ser humano perdería su condición de creatura, puesto que Dios los creó "varón y mujer" para que se complementen (Gn 1,27).

Benedicto XVI, refutando esta "ideología de género" nos recordaba que esto está en evidente contradicción con lo que dicen las Sagradas Escrituras:

Según el relato bíblico de la creación, el haber sido creada por Dios como varón y mujer pertenece a la esencia de la criatura humana. Esta dualidad es esencial para el ser humano, tal como Dios la ha dado. Precisamente esta dualidad como dato originario es lo que se impugna. Ya no es válido lo que leemos en el relato de la creación: «Hombre y mujer los creó» (Gn 1,27). No, lo que vale ahora es que no ha sido Él quien los creó varón o mujer, sino que hasta ahora ha sido la sociedad la que lo ha determinado, y ahora somos nosotros mismos quienes hemos de decidir sobre esto. Hombre y mujer como realidad de la creación, como naturaleza de la persona humana, ya no existen (Benedicto XVI 2012).

En esta ideología se niega a hombres y mujeres su exigencia creacional de ser formas de la persona humana que se integran mutuamente, lo que resulta inaceptable.

El actual Papa Francisco, en su homilía de la audiencia general del miércoles 15 de abril del 2015, abordó la contradicción de esta "ideología de género", que contradice el plan de Dios, al recordar que la "la diferencia entre hombre y mujer no es para la contraposición o la subordinación, sino para la comunión y la generación, siempre a imagen y semejanza de Dios". Nos recuerda el Papa que "solo en el hombre y en la mujer esta lleva en sí la imagen y semejanza Dios... no solo el hombre por su parte es imagen de Dios, no solo la mujer por su parte es imagen Dios, sino también el hombre y la mujer, como pareja, son imagen de Dios". Igualmente, apelando a la experiencia, nos recuerda que el ser humano necesita de la complementariedad, ayuda y reciprocidad mutua: "Estamos hechos para escucharnos y ayudarnos recíprocamente. Podemos decir que sin enriquecimiento recíproco en esta relación - en el pensamiento, en la acción, en los afectos y en el trabajo, también en la fe -, 
los dos no pueden ni siquiera entender profundamente qué significa ser hombre y ser mujer" (Papa Francisco, 2015). También nos alerta sobre el "peligro de esta teoría de género": se pregunta si esta no es expresión de una frustración y de una resignación encaminada a cancelar la diferencia sexual porque no sabe conformarse con ella. Nos recordaba igualmente que la eliminación de las diferencias es el problema y no la solución.

Un segundo aspecto a considerar es que esta ideología de género corroe las bases, el fundamento de la familia, que es también la célula fundamental de la sociedad. Una teórica de la tercera ola del feminismo, a inicios de los '80, la norteamericana Zillah Eisentein, considera que se debe terminar con el "régimen patriarcal" y con el sistema capitalista; con el primero se asegura la destrucción de la familia y del matrimonio; y con la segunda, la abolición de la propiedad privada, que son las fuentes de la marginación de la mujer:

La familia bajo el capitalismo refuerza la opresión de la mujer. La familia apoya al capitalismo económicamente, proporcionando una fuerza de trabajo productiva y el suministro de un mercado productivo masivo. La familia también desempeña un papel ideológico mediante el cultivo de la creencia en la libertad, el individualismo y la igualdad básica de la estructura de creencias de la sociedad" (citada por Laje, 2016, p. 88).

Por ello resulta claro que los enemigos del capitalismo y de la sociedad abierta deben enfocarse en destruir a la familia. Esta idea de género, como algo independiente del hecho natural, busca destruir las instituciones sociales que estarían al servicio del capitalismo: la familia monogámica, la prohibición del incesto y la pedofilia, la heterosexualidad.

Según esta ideología la más perjudicada es la institución familiar: "Si no existe la dualidad del hombre y mujer como dato de la creación, entonces tampoco existe la familia como realidad preestablecida por la creación. Pero, en este caso, también la prole ha perdido el puesto que hasta ahora le correspondía y la particular dignidad que le es propia" (respuesta de Benedicto XVI a Simone de Beauvoir). El Papa Francisco dedicó la homilía del 15 de abril del 2015 al tema de la familia, entendida como la unión del varón y de la mujer y con el sacramento del matrimonio, en una clara alusión a lo que la ideología de género pretende destruir. 
El Sínodo de obispos, en la XIV Asamblea General ordinaria, dedicada a la "vocación y misión de las familias en la Iglesia y el mundo contemporáneo", ve a esta ideología como un gran desafío para la Iglesia:

Hoy, un desafío cultural de gran importancia emerge de la ideología del "gender" que niega la diferencia y la reciprocidad de hombre y mujer. Esta presenta una sociedad sin diferencias de sexo, y vacía el fundamento antropológico de la familia. Esta ideología lleva a proyectos educativos y directrices legislativas que promueven una identidad personal y una intimidad afectiva radicalmente desvinculada de la diversidad biológica entre hombre y mujer $\left(\mathrm{N}^{\circ}\right.$ 8; Papa Francisco, 2015, No 56).

El desafío para la Iglesia, en esta mentalidad extendida, consiste precisamente "en partir de la convicción de que el hombre viene de Dios y vive constantemente en su presencia" (Sínodo de obispos, 2015, No 33); en proclamar que la sexualidad forma parte de un amor auténtico ( $\left.\mathrm{N}^{0} 58\right)$; en contraste con aquella visión que la desvincula del amor auténtico; en proponer sus propios proyectos frente a aquellos que la autoridad pública propone con contenidos en contraste con la visión propiamente humana y cristiana $\left(\mathrm{N}^{\circ}\right.$ 56).

La Iglesia no condena a quienes, de una manera u otra, están inmersos en esta ideología, pero no acepta estas ideologías, como reza el dicho popular "no se condena al pecador, sino al pecado"; adopta una actitud de comprensión, de ayuda, de acompañamiento a quienes han elegido otras opciones que no sean las de su propio sexo, conforme a los ideales bíblico-teológicos:

"Una cosa es comprender la fragilidad humana o la complejidad de la vida, y otra es aceptar ideologías que pretenden partir en dos los aspectos inseparables de la realidad. No caigamos en el pecado de pretender sustituir el creador. Somos creaturas, no somos omnipotentes. Lo creado nos precede y debe ser recibido como don. Al mismo tiempo, somos llamados a custodiar nuestra humanidad y eso significa ante todo aceptarla y respetarla como ha sido creada" (Papa Francisco, Amoris Laetitia", N56).

\section{Enseñanza de la "ideología de género" en los colegios}

En los últimos años muchos gobiernos, llevados por estas ideas liberales presentadas como progresistas y científicas de que el género es una construcción histórica-cultural, han 
tratado de implementar políticas liberales en sus currículos educativos adoctrinando a los niños de que la sexualidad la elige cada uno. Frente a la desigualdad existente entre varones y mujeres se afirma que esta proviene del entorno: la familia, la sociedad, la escuela, que imponen cómo se debe comportar un niño o una niña. Estas diferencias marcadas por la sociedad son las que llevan a la discriminación; y, por lo tanto, la solución a este problema de la desigualdad es que la familia y el entorno dejen de dictar los modos de ser de cada uno y que el lugar donde se debe enseñar esta nueva concepción de la sexualidad debe ser la escuela. "Así los niños y las niñas pueden aprender que no hay diferencias entre ellos, y que perfectamente un hijo puede tener dos papás o dos mamás. El resultado de toda esta confusión es que no se percibe ninguna diferencia entre lo masculino y lo femenino" (Zenteno, 2015) ${ }^{3}$

El Papa Francisco, en la homilía del 3 de octubre del 2016, ha señalado que la ideología de género es una "guerra contra el matrimonio", "una colonización ideológica” y mostró su desacuerdo en la enseñanza de esta ideología en los colegios. Afirmó que una cosa es cuando alguien tiene una tendencia sexual y otra cuando esta es enseñada a los niños, que todos pueden elegir su género. El Papa, desde que fue elegido en el 2013, se ha caracterizado por su posición progresista sobre la homosexualidad: "Si un gay acepta al Señor y tiene buena voluntad, ¿quién soy para juzgarlo?”, preguntó en otra ocasión ${ }^{4}$

Desde que algunos gobiernos han buscado implantar esta ideología de género en la enseñanza se han levantado una serie de protestas: en agosto del 2016, miles de colombianos marcharon contra la ideología de género que aparecía en el borrador de un

\footnotetext{
${ }^{3}$ En esta línea de la ideología de género la legislación de muchos países ha incluido los matrimonios gais, como es el caso de Francia que desde el 18 de mayo del 2013 personas del mismo sexo pueden contraer matrimonio y adoptar niños ("marriage pour tous": "matrimonio para todos"), transformándose en un país no discriminatorio por razones de sexo, religión, orientación sexual. Se formó entonces un movimiento para protestar en contra de esta ley: "La manif pour tous" ("La manifestación para todos") por considerarla lesiva al código civil y a la familia: "Esta (la ley) causa daño al código civil, reemplazando las palabras marido y mujer, padre y madre, por una terminología indiferenciada y unisexual: progenitores. Ella intenta eliminar toda diferenciación sexual como la complementariedad presente en la ley y pone en riesgo los fundamentos de la identidad humana: la diferenciación sexual y en consecuencia la paternidad. Ella abre el camino para un nuevo tipo de paternidad "social", desvinculada de la realidad humana. Crea un marco para un nuevo orden antropológico basado no en el sexo específico sino en la opción sexual: el género" (Zenteno, 2015).

${ }^{4}$ Bastaría con hojear algunos titulares en internet para percatarnos de la importancia que reviste este tema, para ver qué posición adoptar: "eliminan las palabras "padre" y "madre" de los formularios de admisión escolar en España" (09/06/2017); "Aprueban baños transexuales" en la Pontificia Universidad Católica del Perú" (09/06/2017); "critican aprobación de "reforma transexual" en Pontificia Universidad Católica del Perú" (06/06/2017); "1480 carteles recuerdan que "está prohibido rendirse" ante ideología de género en Perú" (01/06/2017).
} 
documento del Ministerio Nacional de Educación, en el que se establecía que "no se nace siendo mujer u hombre, sino que se aprende a serlo, de acuerdo a la sociedad y época en la que se crezca”. La Iglesia Católica colombiana rechazó la implementación de esta ideología en los colegios de Colombia por considerarla destructora: "destruye al ser humano, le quita el contenido fundamental de la relación complementaria entre varón y mujer", según expresó el cardenal Rubén Salazar Gómez.

En el Perú, el sábado 4 de marzo del 2017 se realizó la marcha con el lema "Con mis hijos no te metas", para protestar contra una supuesta inclusión de la "ideología de género" en el currículo Nacional. Esta motivó un diálogo entre el gobierno y los padres de familia para clarificar algunos malentendidos. El Ministerio de Educación expresó que el Currículo Nacional 2017 no promueve tal ideología de género y que tampoco busca promover el cambio de orientación sexual en los niños. Uno de los objetivos del documento, según explicó la Ministra Marilú Martens, es promover el trato igualitario entre hombres y mujeres. Esto llevó a que se clarificaran algunos conceptos como "sexo, "género, "igualdad de género". Sobre la igualdad de género se especificaron los cambios. Antes decía: "todas las personas, independientemente de su identidad de género, tienen el mismo potencial para aprender y desarrollarse plenamente". Ahora dice: "todas las personas tienen el mismo potencial para aprender y desarrollarse plenamente. La igualdad de género se refiere a la igual valoración de los diferentes comportamientos, aspiraciones y necesidades de mujeres y varones". Sobre la construcción de la identidad, antes decía: "vive su sexualidad de manera plena y responsable". Ahora dice: "vive su sexualidad de manera integral y responsable de acuerdo a su etapa de desarrollo y madurez" (Ministerio de Educación, 2017). Como podemos percatarnos los cambios no son sustantivos. A lo que se tiene que estar atento es a que en la práctica se está difundiendo esta ideología. Es ahí donde nuestra tarea de docentes y padres de familia debe encaminarse a prevenir lo riesgoso que sería la difusión de esta ideología.

Creemos que no es suficiente con criticar esta ideología, puesto que muchos elementos culturales han contribuido a la marginación de la mujer; pero tampoco podemos mantenernos en silencio ante el avance de la misma y que abiertamente mina las bases de una antropología cristiana humanista, que concibe al ser humano como una unidad biopsico-social. Nuestra herramienta principal para contrarrestar esta ideología tiene que ser la educación, encaminada a resaltar que el género se fundamenta en la naturaleza humana y no es solo el rol que la sociedad asigna al hombre y a la mujer. Por otra parte, tenemos una 
gran tarea con los padres de familia para rescatar el rol básico que tienen de encaminar la sexualidad de sus hijos, y contrarrestar así al feminismo radical cuyo objetivo, entre otros, es la deconstrucción de la familia.

\section{CONCLUSIONES}

La ideología de género constituye una nueva filosofía sobre la sexualidad, fundamentada en la tesis existencialista "la existencia precede a la esencia"; en contraposición a una concepción unitaria humanista del hombre, que más habla de dimensiones de la persona. Esta ideología afirma que cada quien elige su sexualidad y que esta no es fruto de una supuesta naturaleza humana, sino de condicionamientos histórico-culturales, ideología que contradice el aspecto creatural del ser humano de ser creado por Dios como varón y mujer, a su imagen y semejanza.

Esta ideología no puede ser asumida por la Iglesia católica, por considerarla atea y que destruye una institución fundamental, la familia, a la que considera opresora. Sin embargo, debe adoptar una actitud de comprensión y tolerancia para aquellos que han elegido otra orientación sexual que no sea la de su propia naturaleza.

Hay una clara intención de muchos gobiernos de incluirla en sus programas educativos, pero también hay un evidente rechazo de los padres de familia y de los pastores de algunas iglesias cristianas.

\section{REFERENCIAS}

Benedicto XVI (2012). Ideología de Género, "Falacia profunda". Recuperado el 13 de junio de 2017, de http:/ / www.noticiasglobales.org/comunicacionDetalle.asp?Id=1598

¿Qué es la ideología del género? (2017). Recuperado el 13 de junio de 2107, de http://es.catholic.net/op/articulos/41418/cat/447/que-es-la-ideologia-degenero.htm

Educación, M. d. (2017). Currículo Nacional de la Educación Básica. Lima.

Francisco, P. (15 de Abril de 2015). La ideología de género contradice el plan de Dios. Recuperado el 13 de junio de 2017, de https://www.aciprensa.com/noticias/texto-completocatequesis-del-papa-sobre-ideologia-de-genero-en-la-audiencia-general-19416/

Francisco, P. (19 de marzo de 2016). Exhortación Apostólica postsinodal Amoris Laetitia.

Recuperado el 13 de junio de 2017, de http://w2.vatican.va/content/francesco/es/apost_exhortations/documents/papafrancesco_esortazione-ap_20160319_amoris-laetitia.html 
Laje, Agustín - Márquez, Nicolás. (2016). El libro negro de la nueva iqquierda. Ideología de género o subversión cultural. Buenos Aires: Unión editorial.

Obispos, X. A. (24 de octubre de 2015). Sinodo de los obispos. Recuperado el 13 de junio de 2017, de

http://www.vatican.va/roman_curia/synod/documents/rc_synod_doc_20151026 _relazione-finale-xiv-assemblea_sp.html

Zenteno, J. A. (29 de marzo de 2015). La ideología de género. Recuperado el 14 de junio de 2017, de http:/ / catholic-link.com/2015/04/29/la-ideologia-de-genero-explicadade-forma-genial-en-menos-de-3-minutos/ 